\title{
US refiects on flying eye for transgenic crops
}

Jonathan Knight, San Francisco

The US Environmental Protection Agency (EPA) is hatching a scheme that could let it monitor genetically modified crops from space. Experiments will begin next spring to determine whether subtle differences in the way leaves reflect the Sun's rays can distinguish transgenic from conventional maize.

If it works, the technology would allow the EPA to track farmers' compliance with planting guidelines, and might even spot the emergence of insecticide-resistant pests. This would be a remarkable feat of detection because, to the naked eye, transgenic plants appear identical to normal ones.

Satellite imagery is already a wellestablished agricultural tool. Stressed plants absorb less infrared light than healthy plants, so they appear 'warmer' in infrared photographs. Farmers already make use of images from satellites and aeroplanes to spot thirsty crops, pest infestations and plant diseases. Some large-scale growers use infrared data to classify weeds in their fields to help them decide which herbicides to apply.

All of these things can also be spotted by a farmer in the field - the main advantage of observations from the air is that they allow large areas to be examined quickly. But the EPA's scheme to monitor transgenic crops by satellite would involve discerning more

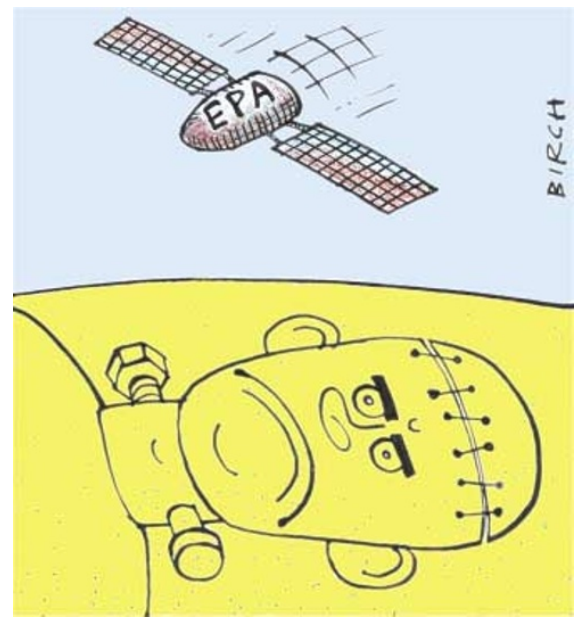

information about a plant from space than an observer could do on the ground.

The idea rests on the possibility that subtle genetic differences between plants might influence the spectral qualities of the solar radiation reflected by the leaves, says project leader John Glaser of the EPA's Cincinnati office. Transgenic varieties would appear different, not because of their inserted genes, but because the starting strains from which they were generated were different from those of conventional crops, he says.

To achieve this sensitivity, computer

models will be needed that can peel away background noise, such as the effects of rainfall, air temperature and pest attack. With this in mind, Glaser has recruited agricultural experts at Pennsylvania State University and the University of Nebraska in Lincoln.

The researchers admit that this may be easier said than done. "The big question is, can we refine it enough to see genetic differences?" says project collaborator Joe Russo, president of ZedX, a company in Bellefonte, Pennsylvania, that builds computer models for agriculture.

The project was born mainly out of concern that overuse of $B t$ maize (corn) which is genetically modified to produce a natural insecticide - will result in the development of resistant insects, rendering the technology useless. US farmers who plant $B t$ maize are required to keep conventional maize on $20 \%$ of their acreage to minimize the risk, but up to one-fifth are thought to be flouting this rule, according to a study released in June (see Nature 424, 116;2003).

In theory, the project could also spot fields of $B t$ maize that are under attack by insects, helping regulators to nip resistance in the bud. The technology, which would not necessarily be limited to maize, could ultimately help to track the use of transgenic crops worldwide, Glaser says.

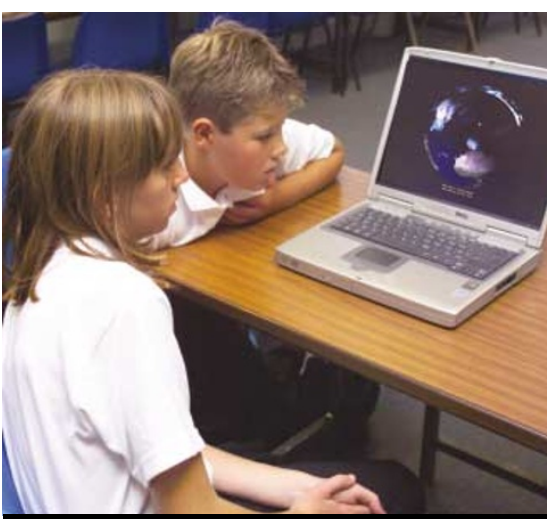

Future in their hands: children at Gosford Hill school in Oxfordshire examine a simulation. machines, researchers hope to identify the ranges of assumptions that are realistic, and hence to generate better predictions of future climate.

Climate models use rules to describe how large-scale factors such as temperature and humidity determine smaller-scale properties such as cloud cover. A range of rules are compatible with observations, so researchers pick the ones that most accurately make the models follow the course of climate in recent decades.

According to Myles Allen, a climate researcher at the Rutherford Appleton Laboratory near Oxford and the originator

of climateprediction.net, it is important to explore the full range of possible rules in order to understand the range of realistic future-climate scenarios.

With time on climate supercomputers scarce, this has not been done. But other big tasks, such as the analysis of extraterrestrial radio signals for signals from intelligent life forms, are already being performed by parcelling out the task to large numbers of personal computers. "Distributed computing projects have attracted hundreds of thousands of participants," says Allen. "Such an ensemble size would form an extraordinary experiment."

Slightly simplified versions of a model that has been developed at the Hadley Centre for Climate Prediction and Research in Bracknell, UK, will be available for downloading from the project website. Each model uses a unique set of rules and simulates a 15-year period, during which the stability of the rules is checked. It then simulates 15 years of current climate conditions, and finally a world with increased greenhouse-gas concentrations. This should produce better estimates for a range of parameters such as temperature increase, and allow scientists to single out the rules for determining the small-scale processes to which climate is most sensitive.

Allen aims to generate publicity at this week's launch, which takes place at the Science Museum in London and coincides with the British Association's annual science festival. The first phase of data collection should be completed by the end of the year, he says, and the first results could be available early in 2004 .

www.climateprediction.net 